
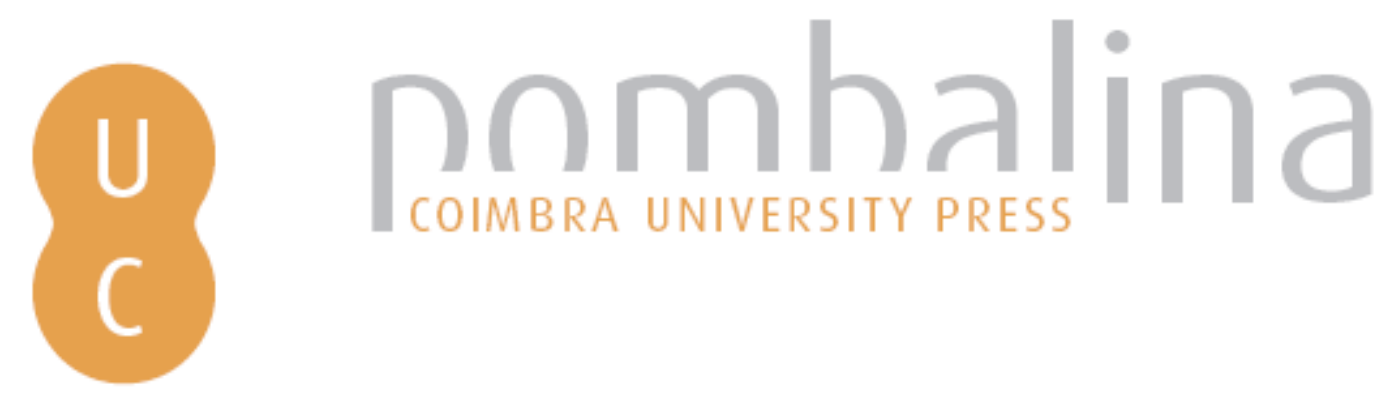

\title{
Minérios de ferro goethícos do quadrilátero ferrífero (Brasil): caracterização com ênfase nas impurezas principais
}

Autor(es): $\quad$ Brandão, P. R. G.; Rocha, J. M. P.; Cançado, R. Z. L.

Publicado por: Imprensa da Universidade de Coimbra

URL

persistente: URI:http://hdl.handle.net/10316.2/31451

DOI: DOI:http://dx.doi.org/10.14195/978-989-26-0534-0_31

Accessed : $\quad$ 26-Apr-2023 11:36:09

A navegação consulta e descarregamento dos títulos inseridos nas Bibliotecas Digitais UC Digitalis, UC Pombalina e UC Impactum, pressupõem a aceitação plena e sem reservas dos Termos e Condições de Uso destas Bibliotecas Digitais, disponíveis em https://digitalis.uc.pt/pt-pt/termos.

Conforme exposto nos referidos Termos e Condições de Uso, o descarregamento de títulos de acesso restrito requer uma licença válida de autorização devendo o utilizador aceder ao(s) documento(s) a partir de um endereço de IP da instituição detentora da supramencionada licença.

Ao utilizador é apenas permitido o descarregamento para uso pessoal, pelo que o emprego do(s) título(s) descarregado(s) para outro fim, designadamente comercial, carece de autorização do respetivo autor ou editor da obra.

Na medida em que todas as obras da UC Digitalis se encontram protegidas pelo Código do Direito de Autor e Direitos Conexos e demais legislação aplicável, toda a cópia, parcial ou total, deste documento, nos casos em que é legalmente admitida, deverá conter ou fazer-se acompanhar por este aviso.

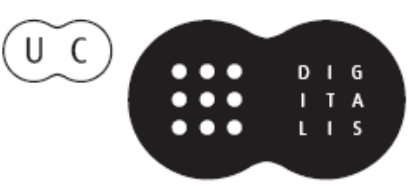





\title{
MINÉRIOS DE FERRO GOETHÍTICOS DO QUADRILÁTERO FERRÍFERO (BRASIL) - CARACTERIZAÇÃO COM ÊNFASE NAS IMPUREZAS PRINCIPAIS
}

\author{
GOETHITIC IRON ORES FROM THE FERRIFEROUS \\ QUADRANGLE (BRAZIL) - CHARACTERIZATION \\ WITH EMPHASIS ON MAIN IMPURITIES
}

Resumo - Amostras de dois minérios de ferro itabiríticos, procedentes do Complexo Mineiro de Alegria, Quadrilátero Ferrífero, Minas Gerais, Brasil, foram caracterizadas, com ênfase nos aspectos mineralógicos, microestruturais e microquímicos. Estes itabiritos derivam de tipologias anteriormente anfibolíticas, mas atualmente as anfíbolas foram totalmente alteradas para uma variedade fibrosa (pseudomórfica) de goethite. Este mineral apresenta-se ainda em outras feiçóes morfológicas como botrioidal e maciça, também abundantes, e por outras mais raras, como porosa e terrosa. A única feição abundante da hematite é a martítica e o quartzo ocorre com frequência. Na granulometria entre 0,150 $\mathrm{mm}$ e $0,010 \mathrm{~mm}$, a libertação é quase total. Ênfase foi dada à análise dos elementos minoritários Al, P e Si (este após a exclusão do quartzo) com microssonda eletrónica WDS. Os estudos indicaram que estes elementos se encontram presentes como solução-sólida na rede cristalina da goethite. Pesquisa por difração de raios-X indicou a compactação desta rede, o que é consistente com a substituição isomórfica do ferro por Al, Si e P. Além disso, nenhum método analítico identificou fases específicas portadores destes elementos.

Palavras-chave - Minério de ferro; Goethite; Impurezas químicas; Hematite; Pseudomorfismo

Abstract - Samples of two itabirite iron ores, from the Alegria Mining Complex, Ferriferous Quadrangle, Brazil, were characterized, with emphasis on mineralogical, microstructural and

1 Depto. Engenharia de Minas, Univ. Federal Minas Gerais UFMG, Belo Horizonte, MG, Brasil; pbrandao@demin.ufmg.br

2 Samarco Mineração S.A., Mariana, MG, Brasil; junia@samarco.com 
microchemical aspects. These types are derived from previous amphibolitic itabirites, but now the amphiboles were totally altered to a fibrous variety (pseudomorphic) of goethite. This mineral is also present in other morphological varieties such as botrioidal and massive, also abundant, and other rarer, like porous and earthy. The only abundant hematite type is the martitic one and quartz occurs frequently. In the particle size range between 0.150 and $0.010 \mathrm{~mm}$, the liberation is almost complete. Emphasis was given to the analysis of the minor elements $A l, P$ and $S i$ (the latter after the exclusion of quartz) with WDS electron microprobe. The studies indicated that these elements are present as solid solution within the crystal lattice of goethite. X-ray diffraction research indicated the compaction of this lattice, what is consistent with the isomorphous substitution of iron by Al, Si and $P$. Besides, no analytical method has identified any specific phase bearing these elements.

\section{Keywords - Iron ore; Goethite; Chemical impurities; Hematite; Pseudomorphism}

\section{1 - Introduçáo}

O mercado mundial de aço tem exigido que as empresas fornecedoras de produtos de minérios de ferro, nos últimos anos, invistam em estudos mineralógicos e tecnológicos em seus minérios, para garantir um maior aproveitamento de seus recursos minerais, uma maior otimização de seus processos produtivos, a redução dos custos de produção e o aumento da qualidade de seus produtos.

As minas de minério de ferro da empresa Samarco Mineração S.A. fazem parte do Complexo de Alegria, localizado nos municípios de Mariana e Ouro Preto, no extremo leste do Quadrilátero Ferrífero, uma importante província mineral que está situada na regiâo centro-sul do Estado de Minas Gerais, Brasil (ROCHA et al., 2009). Os minérios são representados por itabiritos da Formação Cauê do Grupo Itabira do Supergrupo Minas, de idade Proterozoica. As características mineralógicas e microestruturais dos minérios de Alegria são resultado das condiçôes de temperatura e pressão dos processos tectônicos que os afetaram e dos processos intempéricos e supergénicos mais recentes, além de variações intrínsecas às condiçōes de deposição da formação ferrífera (ROCHA, 2008). Dessa forma, ao final da atuaçáo desses processos, tem-se como resultado uma gama variada de tipos de itabirito e rochas associadas.

As minas do Complexo de Alegria possuem reservas muito grandes de minério de ferro itabirítico. Uma parte majoritária destas reservas apresenta goethite como mineral portador de ferro principal, o segundo em abundância a hematite, sendo o principal mineral de ganga o quartzo.

Grande parte do Complexo de Alegria é lavrada pela Samarco Mineração S.A., que está entre os grandes produtores mundiais de pelotas de minério de ferro.

Os minerais componentes dos minérios de ferro de Alegria apresentam-se em diversas feiçôes e tramas microestruturais. Assim, a goethite mostra as seguintes feiçôes principais: botrioidal, maciça, porosa, terrosa e fibrosa (ROCHA et al., 2011). Esta última feição da goethite é pseudomórfica de anfíbola preexistente, que atualmente acha-se totalmente alterada para goethite (ROCHA et al., 2009) e algum quartzo. A hematite está presente principalmente na feição martítica.

Vários desses itabiritos goethíticos apresentam teores variáveis, às vezes acima das especificaçōes técnicas, dos elementos alumínio, silício e, algumas vezes, também fósforo. 
O agravante é que esse teor se mantém nos concentrados do minério, após a remoção do quartzo, por flotação (flutuação). Em algumas amostras, minerais portadores de alumínio e silício foram detectados, como caulinite e gibbsite, mas em outros não (ROCHA et al., 2011). Assim, suspeita-se que estes elementos químicos podem estar presentes como soluçáo-sólida na goethite e/ou na hematite ou mesmo podem ocorrer como inclusóes minoritárias e muito pequenas nestes minerais principais.

Para tentar esclarecer a ocorrência das impurezas, analisadas na forma de $\mathrm{Al}_{2} \mathrm{O}_{3}, \mathrm{SiO}_{2}$ e $\mathrm{P}$, usou-se principalmente a difração de raios-X e a microanálise por microssonda WDS. Também foram usadas as microscopias óptica e eletrónica de varrimento.

\section{2 - Materiais e equipamento}

Duas amostras de itabiritos goethíticos foram coletadas na Mina de Alegria para a realização desta pesquisa, amostras A61 e A62. Ambas mostravam teores significativos das impurezas químicas mencionadas, mas tinham aspecto macroscópico diferente, sendo que na A62 notavam-se fibras milimétricas e submilimétricas, mas na A61 essas fibras não foram observadas.

As amostras foram preparadas da seguinte maneira: elas foram britadas, moídas e foi feita deslamagem, em equipamentos em escala de bancada. A granulometria ficou, então, entre $0,150 \mathrm{~mm}$ e $0,010 \mathrm{~mm}$.

Utilizou-se a difração de raios-X para identificar as fases minerais presentes, numa abordagem semiquantitativa. Numa segunda etapa, foi feita a determinação de parâmetros da rede cristalina do mineral goethite, para verificar a ocorrência ou não de deformação desta rede, devido à presença de outros ióes, além daqueles componentes do mineral puro, ou seja, $\mathrm{Fe}^{3+}, \mathrm{O}^{2-}$ e $\mathrm{OH}^{-}$. O equipamento usado foi o difratómetro de raios-X para amostras em pó, marca Philips (Panalytical), sistema X'Pert-APD, controlador PW 3710/31. Utilizou-se tubo de ânodo de cobre.

Os estudos de microestrutura e microanálise foram efetuados principalmente com o microscópio eletrónico de varrimento (MEV) marca Jeol, modelo JSM-5410, com um microanalisador de raios-X dispersivo em energia (EDS) marca Noran, modelo TN-M3055.

Microanálises quantitativas foram executadas em microssonda eletrônica com espectrómetros dispersivos em comprimento de onda (WDS), JEOL, modelo JXA8900RL.

Alguns estudos microestruturais de alta resolução foram feitos com o microscópio eletrónico de varrimento (MEV) com canhão de emissão por efeito de campo (field-effect gun - FEG), marca FEI, modelo Quanta 200 FEG.

Por último, mas não menos importante, efetuou-se estudo de microscopia óptica, por meio de secçóes polidas, com o microscópio marca Leitz/Leica, modelo Orthoplan Pol.

\section{3 - Resultados e discussão}

A tabela 1 mostra a composição química das duas amostras de itabiritos. As análises foram efetuadas por via úmida (dicromatometria), para a determinação das percentagens de $\mathrm{Fe}$ (ferro total) e $\mathrm{FeO}$ e, em espectrómetro de emissão a plasma (ICP), para a determinação dos teores de $\mathrm{Al}_{2} \mathrm{O}_{3}, \mathrm{P}$ (fósforo) e $\mathrm{MnO}_{2}$. Os valores de perda por calcinação (PPC) foram feitos por gravimetria. Os teores de $\mathrm{SiO}_{2}$ foram definidos por diferença. 
Tabela 1 - Composição química dos itabiritos (\% em massa).

\begin{tabular}{|l|c|c|c|c|c|c|c|}
\hline & $\mathrm{Fe}$ total & $\mathrm{FeO}$ & $\mathrm{SiO}_{2}$ & $\mathrm{Al}_{2} \mathrm{O}_{3}$ & $\mathrm{P}$ & $\mathrm{MnO}_{2}$ & $\mathrm{PPC}$ \\
\hline Amostra A61 & 43,58 & 1,79 & 33,10 & 0,82 & 0,012 & 0,07 & 3,68 \\
\hline Amostra A62 & 46,06 & 0,26 & 26,67 & 0,27 & 0,098 & 0,02 & 6,96 \\
\hline
\end{tabular}

Verifica-se que os teores de fósforo são relativamente altos (SOUZA JR. \& BRANDÃO, 1996), especialmente para a amostra A62. O maior valor da PPC é consistente com uma maior quantidade de goethite na amostra A62 (tabela 2); também, o teor mais alto de FeO é compatível com a percentagem mais elevada de magnetite no itabirito A61.

As composiçôes mineralógicas estão indicadas na tabela 2. Foram usados os métodos de difração de raios-X e análise modal em microscopia óptica de luz refletida. Cumpre observar os teores inexpressivos de hematite lamelar e os elevados conteúdos de hematite martítica e de goethite. Como se trata de amostras brutas de itabirito, os teores de quartzo são elevados.

Tabela 2 - Composição mineralógica dos itabiritos (\% em massa).

\begin{tabular}{|l|c|c|c|c|c|}
\hline & Goethite & $\begin{array}{c}\text { Hematite } \\
\text { martítica }\end{array}$ & $\begin{array}{c}\text { Hematite } \\
\text { lamelar }\end{array}$ & Magnetite & Quartzo \\
\hline Amostra A61 & 30 & 35 & 0 & 8 & 27 \\
\hline Amostra A62 & 48 & 21 & 1 & 4 & 26 \\
\hline
\end{tabular}

Os teores dos elementos $\mathrm{Al}$, Si e P são importantes nos concentrados, após a concentração dos minérios itabiríticos. Estes elementos minoritários são usualmente reportados como $\mathrm{Al}_{2} \mathrm{O}_{3}$, $\mathrm{SiO}_{2}$ e P. Ressalte-se que aqui se refere ao Si restante nos concentrados, após a remoção da quase totalidade do quartzo original. Estudos anteriores sugeriram que estes elementos ocorrem principalmente nas diversas feiçóes da goethite presentes nos itabiritos (SANTOS et al., 2002).

Para se verificar a possibilidade desses elementos estarem presentes na rede cristalina da goethite, como substituição isomórfica, foi realizada a análise por difração de raios-X, para verificação de distorçóes na cela unitária deste mineral (NORISH \& TAYLOR, 1961). Para esta determinação, usou-se o próprio quartzo natural das amostras como padrão interno, para correção das distâncias interplanares deste mineral e, principalmente, da goethite.

Como se verifica na tabela 3 , houve contração para ambas as reflexóes de difração estudadas na goethite correspondentes aos índices (110) e (111). Comprovou-se, assim, que ocorreu compactação da cela unitária da goethite, maior na amostra A62, mas ainda bem significativa na amostra A61.

Tabela 3 - Contração de distâncias interplanares da cela unitária da goethite por difração de raios-X.

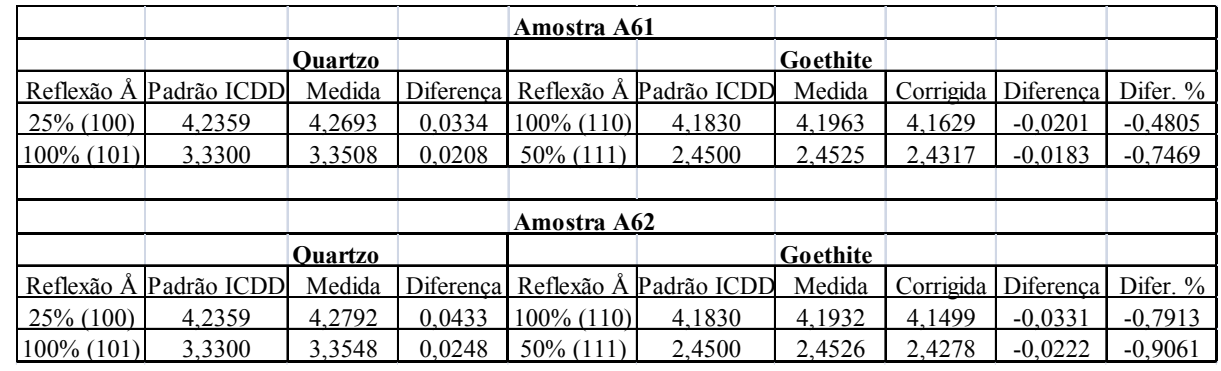


Esta contração muito provavelmente está associada à substituição isomórfica do $\mathrm{Fe}^{+3}$ na rede cristalina da goethite pelo ião $\mathrm{Al}^{+3}$ (NORISH \& TAYLOR, 1961), mas também pelos iôes $\mathrm{Si}^{+4}$ e $\mathrm{P}^{+5}$, pois todos têm raio iónico menor do que o $\mathrm{Fe}^{+3}$.

Nesta altura, é essencial provar-se, ou não, a presença desses elementos em cristais de goethite (e dos outros minerais também). A microanálise EDS da Fig. 1 mostra claramente a presença dos elementos $\mathrm{Al}$, Si e P em cristal típico de goethite na amostra A62, além dos elementos maioritários $\mathrm{Fe}$ e $\mathrm{O}$ (oxigénio).

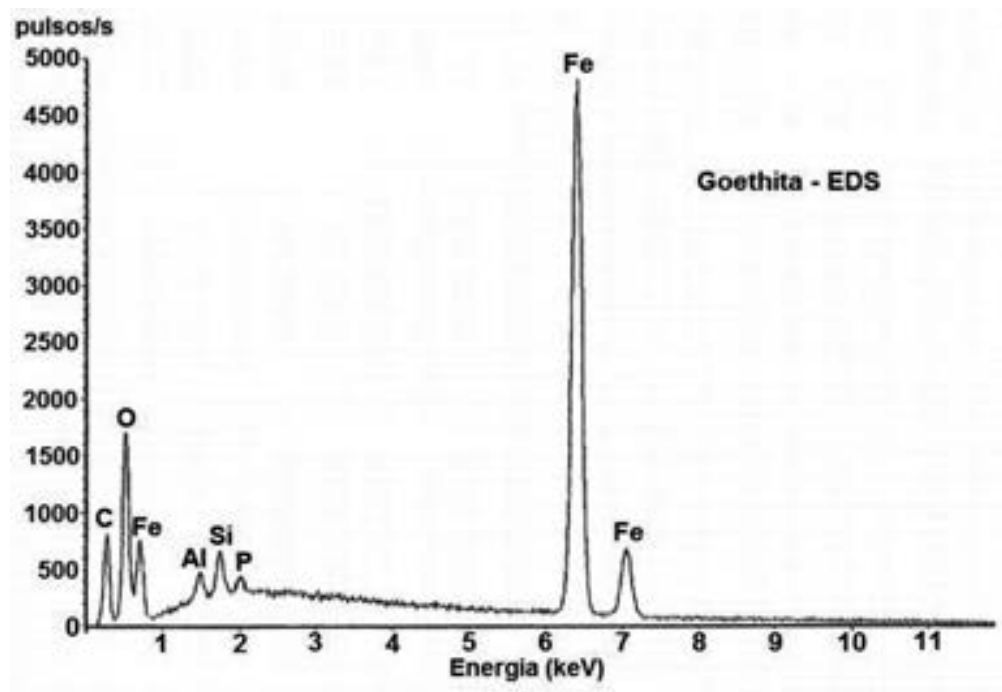

Fig. 1 - Microanálise EDS em cristal típico de goethite da amostra A62.

Este resultado analítico confirmou-se para todas as feições da goethite, evidentemente, com variaçóes nas alturas dos picos dos elementos minoritários. Ressalte-se que o elemento P nem sempre foi detectado, principalmente na amostra A61.

Como se sabe, os resultados de EDS são semiquantitativos, em geral, apesar de serem muito úteis em estudos preliminares e exploratórios de caracterização. Assim, microanálises quantitativas foram executadas em microssonda WDS. Os resultados estão sumariados na tabela 4. Verifica-se que todos os elementos minoritários foram detectados, em concentraçóes significativas, isto é, acima dos respectivos limites de detecção, em todas as análises de goethites, nas duas amostras. Ao contrário, na hematite martítica, apenas o elemento Si apresentou concentração significativa na amostra A61; já na amostra A62, a hematite martítica mostrou teor baixo para $\mathrm{Si}$ e muito baixos, na média, para $\mathrm{Al}$ e $\mathrm{P}$.

Verifica-se que a feição goethite botrioidal da amostra A61 mostrou os maiores teores de $\mathrm{Al}$ e $\mathrm{Si}$, enquanto as feiçóes fibrosa e maciça da amostra A62 apresentaram teores relativamente altos de $\mathrm{Si}$ e medianos de Al. A goethite fibrosa da amostra A62 teve os valores relativos mais elevados de fósforo, que também foram significativos na feição goethite maciça (tabela 4). 
Tabela 4 - Microanálises WDS dos itabiritos A61 e A62 (dados em \% em massa).

\begin{tabular}{|l|c|c|c|c|}
\hline \multicolumn{5}{|c|}{ Limites de detecção } \\
\hline Óxidos & $\mathrm{Al}_{2} \mathrm{O}_{3}$ & $\mathrm{SiO}_{2}$ & $\mathrm{P}_{2} \mathrm{O}_{5}$ & $\mathrm{Fe}_{2} \mathrm{O}_{3}$ \\
\hline & 0,053 & 0,045 & 0,092 & 0,214 \\
\hline
\end{tabular}

\begin{tabular}{|c|c|c|c|c|}
\hline & \multicolumn{2}{|c|}{ Amostra A61 } & & \\
\hline & \multicolumn{3}{|c|}{ Goethite botrioidal } & \\
\hline Média & 2,31 & 3,62 & 0,05 & 75,62 \\
\hline Desvio padrão & 2,27 & 1,41 & 0,05 & 5,07 \\
\hline Menor valor & 0,18 & 1,86 & 0,00 & 61,88 \\
\hline Maior valor & 9,72 & 9,27 & 0,21 & 85,00 \\
\hline \multicolumn{5}{|c|}{ Hematite martítica } \\
\hline Média & 0,00 & 0,76 & 0,00 & 99,22 \\
\hline Desvio padrão & 0,00 & 0,18 & 0,00 & 0,21 \\
\hline
\end{tabular}

\begin{tabular}{|l|c|c|c|c|}
\hline \multicolumn{5}{|c|}{ Amostra A62 } \\
\hline & Goethite & fibrosa & \\
\hline Média & 0,31 & 1,67 & 0,31 & 83,37 \\
\hline Desvio padrão & 0,28 & 0,55 & 0,19 & 4,25 \\
\hline Menor valor & 0,00 & 0,32 & 0,00 & 77,38 \\
\hline Maior valor & 1,01 & 2,85 & 0,72 & 96,59 \\
\hline & Goethite & maciça & & \\
\hline Média & 0,50 & 3,17 & 0,15 & 80,85 \\
\hline Desvio padrão & 0,61 & 1,14 & 0,15 & 1,60 \\
\hline Menor valor & 0,01 & 0,96 & 0,02 & 77,64 \\
\hline Maior valor & 2,62 & 5,05 & 0,73 & 83,29 \\
\hline & Hematite & martítica & & \\
\hline Média & 0,12 & 0,64 & 0,08 & 96,47 \\
\hline Desvio padrão & 0,19 & 0,54 & 0,14 & 2,74 \\
\hline Menor valor & 0,00 & 0,06 & 0,00 & 90,95 \\
\hline Maior valor & 0,66 & 1,72 & 0,54 & 99,45 \\
\hline
\end{tabular}

A seguir, descrevem-se os aspectos microestruturais mais importantes das amostras estudadas (SANTOS et al., 2002; SANTOS \& BRANDÃO, 2003). As legendas dos minerais e feiçôes morfológicas microestruturais são as seguintes: $\mathrm{Hm}=$ hematite martítica; $\mathrm{Gb}=$ goethite botrioidal; $\mathrm{Gf}=$ goethite fibrosa; $\mathrm{Gm}=$ goethite maciça; $\mathrm{Gp}=$ goethite porosa; $\mathrm{M}=$ magnetite; $\mathrm{Q}=$ quartzo; $\mathrm{R}=$ resina de impregnação; $\mathrm{Po}=$ poro.

As Figs. 2 e 3 ilustram os principais minerais e suas morfologias na amostra A61. As partículas estão praticamente todas libertadas e são compostas de goethite botrioidal, hematite martítica e quartzo. Na Fig. 3, mostra-se partícula de origem martítica, composta de hematite martítica, com a típica trama em treliça (MORRIS, 1985), e goethite maciça (não abundante nesta amostra). Há várias partículas anédricas e angulosas de quartzo nas Figs. 2 e 3. 


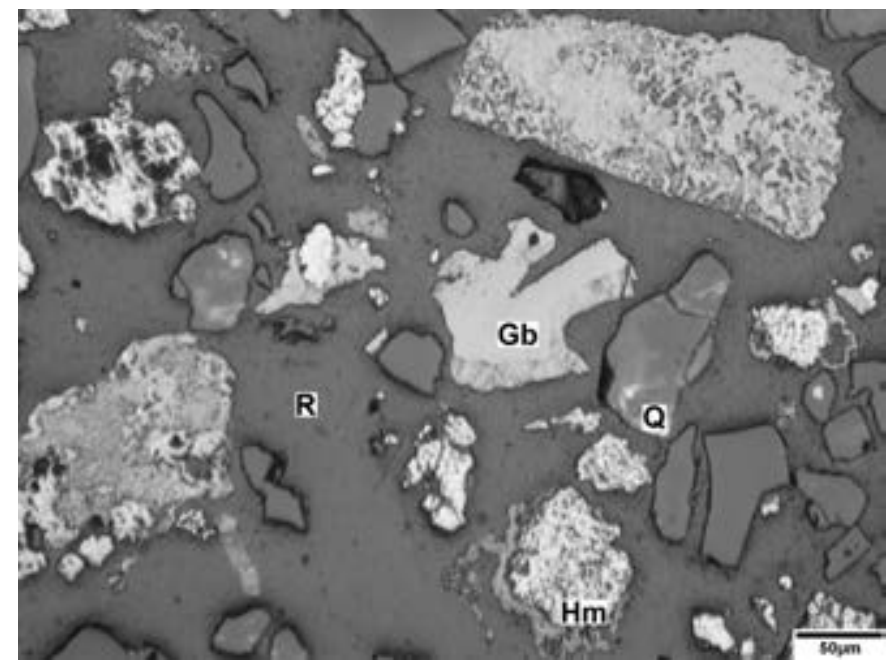

Fig. 2 - Amostra A61: partículas, quase todas libertadas, compostas de goethite botrioidal, hematite martítica e quartzo. Observação por microscopia óptica de luz refletida, nicóis descruzados.

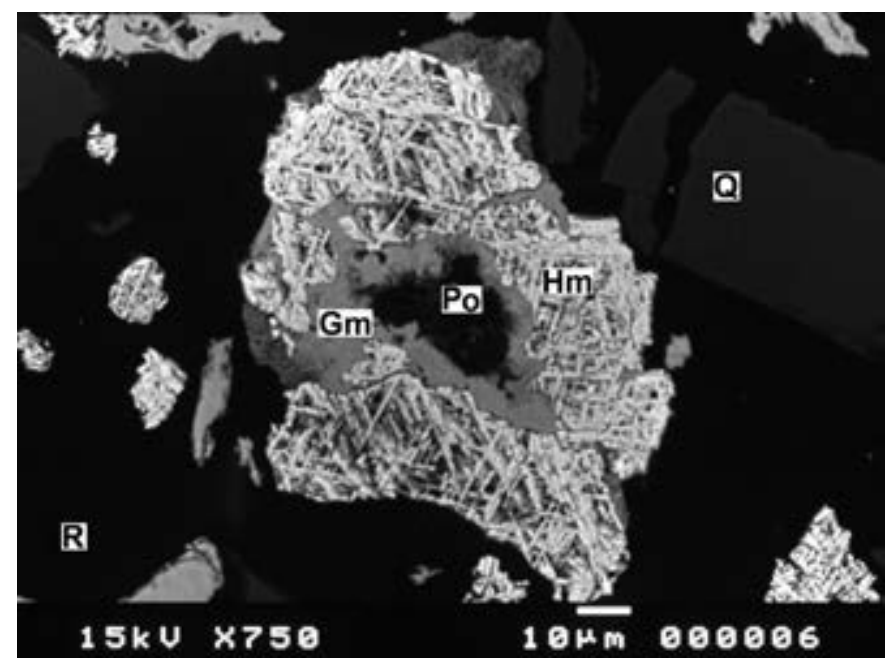

Fig. 3 - Amostra A61: partícula de origem martítica, composta de hematite martítica e goethite maciça; à direita, partículas de quartzo; todas as partículas estão libertadas. Observação por microscopia eletrónica de varrimento (MEV), imagem de eletrōes retrodifundidos.

Aspectos microestruturais importantes da amostra A62 estáo ilustrados nas Figs. 4 e 5. Há predominância da goethite fibrosa, com ocorrência bem menor das variedades botrioidal e maciça. Também há ocorrência abundante de hematite martítica e quartzo. Os demais aspectos são similares aos da amostra A61. 


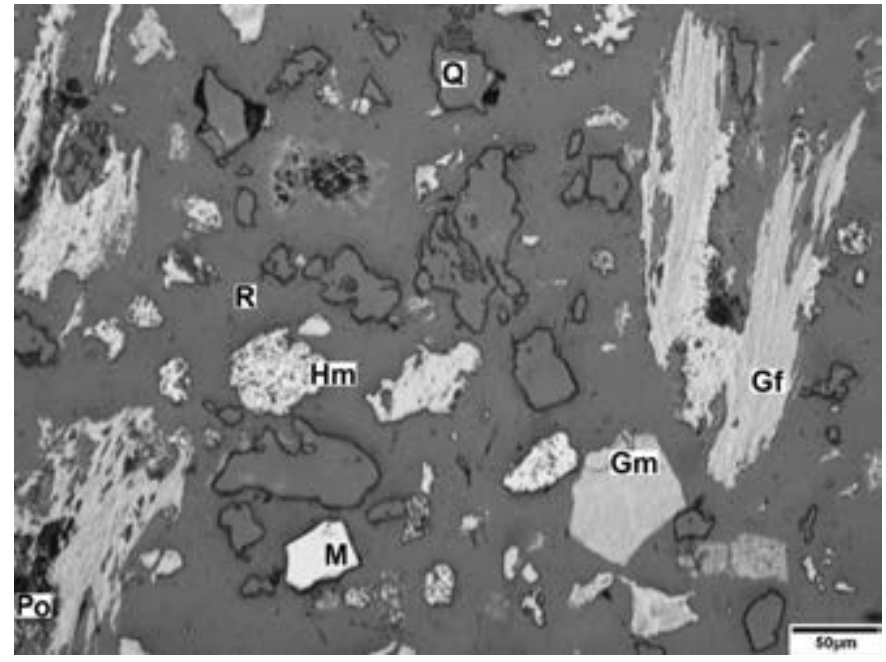

Fig. 4 - Amostra A62: partículas, quase todas libertadas, compostas principalmente de goethite fibrosa, poucas goethites maciça e botrioidal; presença de hematite martítica, quartzo e uma única magnetite. Observação por microscopia óptica de luz refletida, nicóis descruzados.

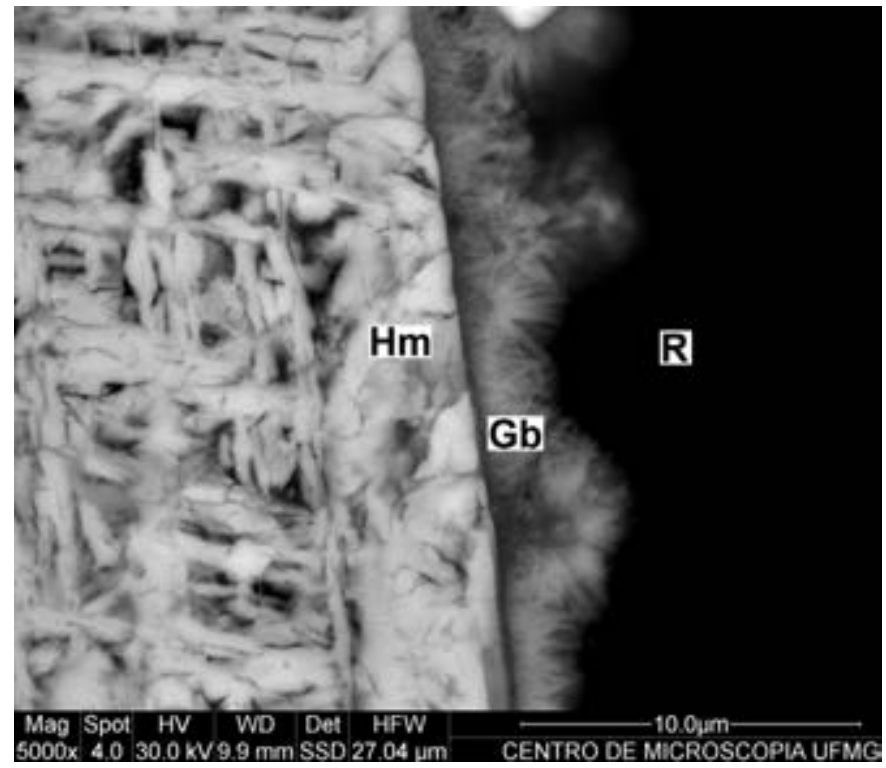

Fig. 5 - Amostra A62: detalhe da borda de gráo de hematite martítica, com a típica trama em treliça, recoberta com fina crosta de goethite botrioidal. Observaçấo por microscopia eletrónica de varrimento de alta definição (MEV-FEG), imagem de eletrōes retrodifundidos. 
Mesmo com grandes aumentos, como na Fig. 5, e em outras com ampliação maior ainda, analisadas no MEV-FEG, não se detectou qualquer fase portadora de alumínio e fósforo. Excluindo o quartzo, que é facilmente separável por flotação (flutuação), resta ainda o teor de $\mathrm{Si}$, que tampouco pode ser associado a alguma inclusão na goethite e nem na hematite.

\section{4 - Conclusóes}

Conclui-se que os elementos minoritários Al, Si e P encontram-se principalmente associados à goethite, em todas as suas feiçôes morfológicas, principalmente a fibrosa e a botrioidal, seguidas da feição maciça.

A hematite martítica apresentou-se bem mais pura, sendo detectados teores significativos apenas de silício.

Nenhum método analítico utilizado, inclusive a microscopia eletrónica de varrimento de alta resolução (MEV-FEG) e a difração de raios-X, identificou qualquer inclusão portadora potencial destes elementos. Como a difração de raios-X comprovou a compactação da célula unitária da goethite, o que é indicativo de substituição isomórfica por iôes menores que o $\mathrm{Fe}^{3+}$, conclui-se que os elementos $\mathrm{Al}$, Si e P se encontram presentes como solução-sólida na rede cristalina da goethite.

Agradecimentos - Os autores agradecem à Samarco Mineração S.A. pelo fornecimento e análises químicas das amostras. PRGB agradece ao CNPq-Brasil o apoio pela bolsa de pesquisador, bem como os recursos para a pesquisa.

\section{Referências Bibliográficas}

MORRIS, R. C. (1985) - Genesis of iron ore in banded iron-formation by supergene and supergene-metamorphic processes - a conceptual model. In: Handbook of Strata-Bound and Stratiform Ore Deposits. Netherlands: Elsevier Science Publishers, 13, Cap. 2, p. 73-235.

NORISH, K. \& TAYLOR, R. M. (1961) - The isomorphous replacement of iron by aluminium in soil goethite. Journal of Soil Science, 12, p. 294-306.

ROCHA, J. M. P. (2008) - Definição da tipologia e caracterização mineralógica e microestrutural dos itabiritos anfibolíticos das Minas de Alegria da Samarco Mineração S.A. - Minas Gerais. Belo Horizonte: Escola de Engenharia da UFMG. 2vols. Tese de Doutorado apresentada ao Curso de Pós-Graduação em Engenharia Metalúrgica e de Minas da Universidade Federal de Minas Gerais, 460 p.

ROCHA, J. M. P., BRANDÃO, P. R. G. \& CANÇADO, R. Z. L. (2011) - Characterisation of the amphibolitic itabirites of the Alegria Mines, Minas Gerais, Brazil. Proceedings, Geomin 2011 - 2nd. International Seminar on Geology for the Mining Industry, Antofagasta, Chile, p. 1-10.

ROCHA, J. M. P., BRANDÁO, P. R. G. \& CHISTE, J. P. (2009) - Origem da goethita fibrosa dos itabiritos anfibolíticos das minas de Alegria - Samarco Mineração S.A. Anais do $10^{\circ}$ Simpósio Brasileiro de Minério de Ferro, Ouro Preto, MG, Assoc. Brasileira Metalurgia, Materiais e Mineraçâo (ABM), São Paulo, p. 1-12.

SANTOS, L. D., BRANDÃO, P. R. G. \& PERES, A. E. C. (2002) - Caracterização mineralógica de minérios de ferro enfatizando a determinação de fases aluminosas. Metalurgia \& Materiais, Caderno Tecnológico, Tecnologia Mineral, 58, p. 12-17. 
SANTOS, L. D. \& BRANDÃO, P. R. G. (2003) - Morphological varieties of goethite in iron ores from Minas Gerais, Brazil. Minerals Engineering, 16, p. 1285-1289.

SOUZA Jr., M. \& BRANDÁO, P. R. G. (1996) - Minério de ferro itabirítico anfibolítico da Mina de Alegria - Caracterização tecnológica. I Simpósio Brasileiro de Minério de Ferro: Caracterização, Beneficiamento e Pelotização, Ouro Preto, p. 1-18. 